\title{
The Paradox of Control: Visual Clue vs. Auditory Instruction in Game Designing
}

\author{
Yusup Sigit Martyastiadi ${ }^{1,2}$ \\ ${ }^{1}$ Faculty of Art \& Design, Universitas Multimedia Nusantara \\ ${ }^{2}$ Doctoral Student of Graduate School, Indonesia Institute of the Arts Yogyakarta \\ yusup.martyastiadi@umn.ac.id
}

\begin{abstract}
Visual clue and auditory instruction are information that used in games. The genuine information is developed on game design conceptualization. This paper explains the study of the paradox of control, which was applied in the process of game designing. Basically, the research investigates the differences of powerful game information between visual clue and auditory instruction to gain complexity of game levelling. The research method used game design experiments, playing observations, and the interview to clarify the respondents' decision-making. The visual clues and auditory instructions were occurred randomly based on the path of the respondents' chosen. However, in one level of observation, the information of visual clue \& auditory instruction were happening together in the same time and those were contradictive each other. This condition was called the paradox of control on information handling in the game. Interestingly, in this circumstance, most of the respondents decided to follow the visual clues, although it was not the right direction. That condition potentially led by visual perception. This paper will describe the respondents' motivation on their decision-making. Finally, the result of this study could give recommendation for level designers in game designing, especially on complexity of the challenge in the game's dramatic element.
\end{abstract}

Keywords: paradox of control, visual clues, auditory instruction, visual perception, players' decision-making

\section{INTRODUCTION}

The research objective is investigating the paradox of control to gain challenges in game designing. The goal of this study would be used as a recommendation for developing game challenges as part of the dramatic element of the game design. The background of this study was triggered by players' decision-making observation during playing games. Trendily, the players influenced by visual clues when doing game play, although there were auditory clues in the game environment. The curiosity of the study was "where is the stand of sound game to direct players' decision-making?" and "what kind of sound functionality in the game play?". However, this research would not pay a lot of attention on the auditory perspective. The sound game as a cross modal with visual perception will be contradicted to investigate the players' decision-making. 
In the process of learning in game designing, Bates (2004) states that the students as designers have to learn about what gamers' thought. The game designer cannot think about what their want in the game. The perspective is thinking of designer's plan for gamers' wish in the game. The good game can attract players to play and accomplish the goal. The one of great game indicator is player immersed in the game world. On the other hand, the players should be conscious on where, why and what they are staying on doing the game stuffs. This condition is called grounding the player (Bates, 2004).

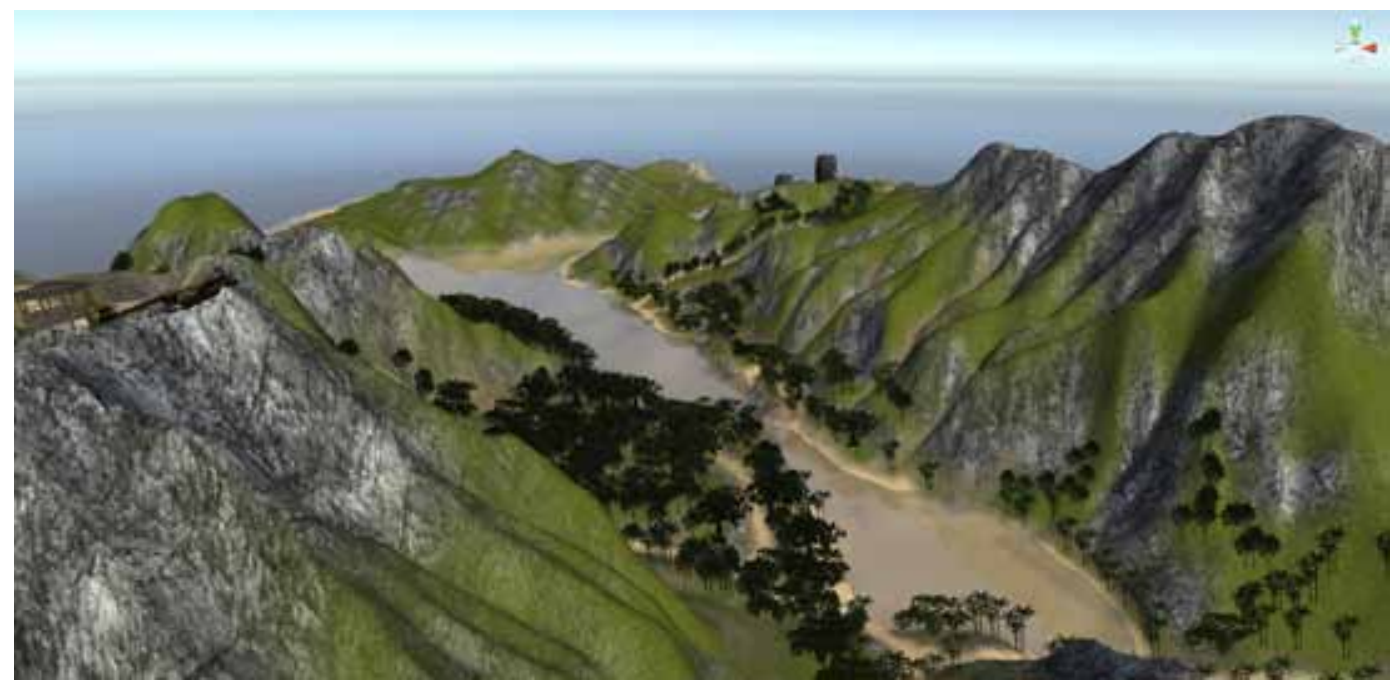

Figure 1. Game Environment Looks

In the game designing point of view, designers suppose to be understood what will be expect on the players' head and anticipate their reaction on complexity game situations. Bates (2004) points-out the important of player empathy by ensure interaction between the players and the game is going smooth. Moreover, Gorini et al. (2011) states that combination of immersion and narrative are significant features to generate an effective experience with virtual world. This great interaction would lead better experience in game play for users.

In the formal elements of the game, sometime the play needs conflict by creating rules, procedures, and situations (Fullerton, 2008). It is needed to make game just not easy to mastering and making interesting game flow. By gaining complexities with creating conflicts and challenges could boost the interactivity. For instance, constructing paradoxical circumstances could improve enjoyment experiences.

In term of game design, the paradox of control is a situation that players are not actually in full control of their plays. The paradox of control is commonly used in some games to attract more game players' challenge. The paradox uses difficult situation that planned by designer. In some cases, Fullerton (2008) states that players enjoy this personal conflict condition on the game. The paradox of control is also one factor of the pleasure of the game. It means, joyful playing game could be gained by making complex setting. Csikszentmihalyi (1990) points-out that this enjoyment on the sense of experiencing control in knotty control, actually the gamers are not in full control due to unsure outcome. 
On the other hand, this paradoxical sensation could be applied in the Csikszentmihalyi's theory about 'Flow', especially for generating balance situation on psychological of the gamers by adjusting the challenges. Basically, the gamers' skills/abilities need to be improved in line with the growth of the challenges. The meaning is the game design considers that gamers should be inside the flow channel, otherwise they will feel bored or frustrated, as showed on Figure 2 below (Fullerton, 2008).

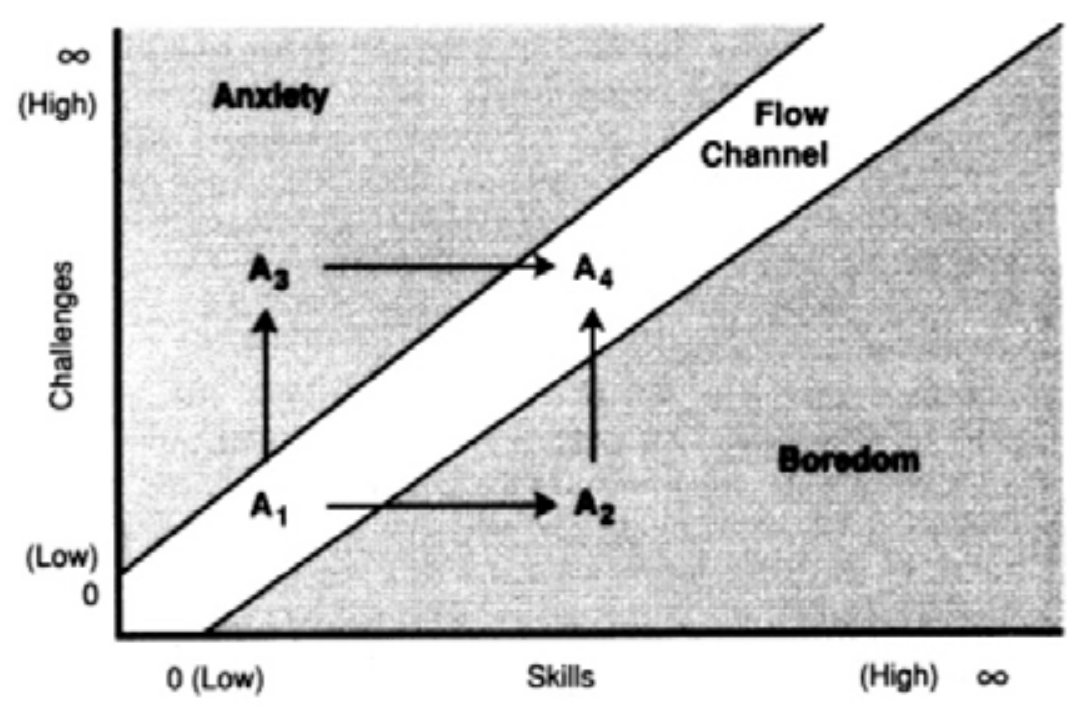

Figure 2. Flow Diagram (Csikszentmihalyi, 1990)

\section{METHODOLOGY}

This research is mixed methodology which using quantitative and qualitative methods. The study involved 27 students, majoring in Animation, Universitas Multimedia Nusantara, who took 3D Game Design subject. The subject of 3D Game Design, commonly, taken by about 25 - 30 students for each semester as an elective subject. This research was also part of their learning about develop challenge for design levelling. In general, they learned how to develop 3D game as designers and practice their knowledge on their game projects. Sequence of lesson, they applied game theories including formal elements, dramatic elements and finally, system dynamics of the game.

The study divided in three steps, which are experiment, playing observation, and interview. First of all, the experiment was set-up on game lab with UNITY3D software. There were challenge conceptualization, implementing the concept for cross modal visual clues \& auditory instruction, applying the paradox of control, and game testing through the game engine (without publishing the game). Secondly, the students asked to play the game and I did observation on that. The observation was done about 2.5 hours. I went to each student for watching their play and wrote their decision-making on the game play. The last, for confirmation, I conducted interviews with the students by clarified their considerations on taking step for each pathway they decided. There were some qualitative arguments when making judgments of their path for game achievement. 


\section{EXPERIMENTS}

The materials of the game world used 'Island Demo Project' assets that belong to UNITY3D, a 3D game engine software; except some game objects, such as sign system (turn left, turn right, and camp sign), survivor marker (food wrap, soft drink cans), and auditory instruction, which made by researcher.

\section{Conceptualization}

This experiment used mechanism of 'search and rescue' (SAR) scenario game as an adventure game. Generally, the design was searching and rescuing survivor who lost in the mountainous jungle. The players asked to explore the jungle and seek the lost person. The players guided by visual clue and auditory instruction, however, they supposed to make decision on their own judgement. In term of game design, decision making means action for chose given task/quest in the game world. The tasks decision could be a pathway, an answer of puzzle, a strategy, and so on.

The plot of this game level used modulated plot, which referred to Meadows (2003) concept. The modulated plot means the users could make decision freely by choosing non-linier nodes, so they have the own pathway of interactivity. However, actually the designer already modulates the plot of decision points, it means users' choices are not really boundless.

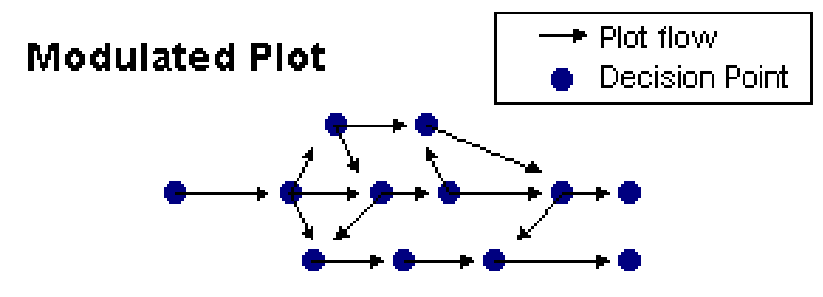

Figure 3. Modulated Plot

(http://zach.tomaszewski.name/uh/ics699/modulated.gif)

The design of game plot for the experiment is as showed in figure 4 . There are three main experiments, such as cross modal visual clues \& auditory direction, auditory instruction without sign system, and paradoxical clues. 


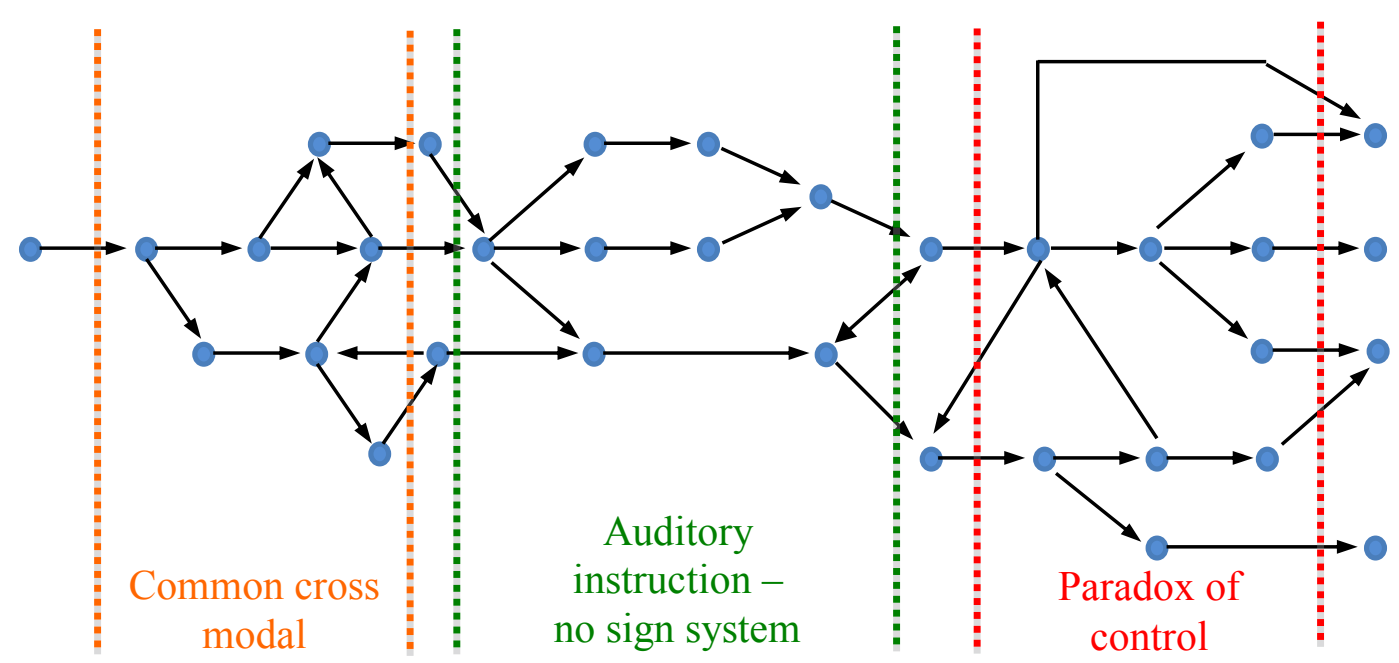

Figure 4. Design of SAR Game Plot

\section{Implementation Concept}

All of game objects, including visual and audio, are integrated in the game engine. Basically, all of assets are located based on decision point (as showed in figure 4) and the game scenario. First of all, the experiment begin with easy task that the respondents will follow the cross modal clues and they are not contradictive command. The gamers will be helped by sign system, such as sign of turn right/left and auditory instruction. Secondly, there is only auditory command, which heard by the respondents for each challenge and no sign system aid. The respondents suppose to make their own decision according to their perception and game scenario. The quests are finding the shelter and finding the potential pathway of the survivor. The last, the concept of paradox of control is implemented on this level. There are some contradictive clues between visual information and auditory instruction. This challenge experiments two typical of paradoxical clues, which are simple complexity and difficult complexity. The difference is just on the number of paradox clue in each challenge.

\section{OBSERVATION \& DISSCUSSION}

The perpetual term on cross modal perception in the game is needed to boost immersion. The meaning that dramatic element of the game grows challenge and ability. Roettl \& Terlutter (2018) describe that the term "perceptual" refers to real-time feedback towards an object in a person's setting and involves real time responses from the personal emotional and cognitive processing or sensory system. Moreover, O'leary \& Rhodes (1984) explains that the perception has function to analyse the sensory collection into objects. This is the important of perception that influences the decision-making.

We focus on the interview clarification based on respondents' decision-making. Generally, there were three types of cross modal clues on this study, which are common visual clues (signage) \& auditory direction, auditory instruction without sign system, and paradoxical clues. 


\section{Cross Modal Visual Clues \& Auditory Direction}
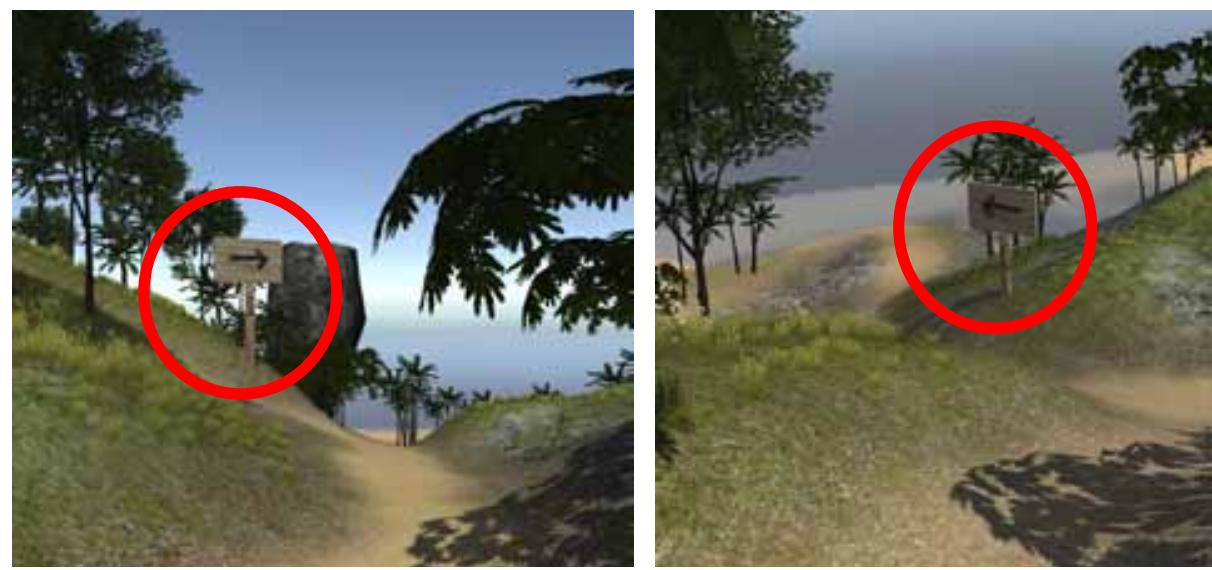

Figure 5. Sign System \& Voice-over Direction to Turn Left/Right

This common cross modal is simple to understand, because of commonsense in daily life, as illustrated in figure 5. Most of respondents followed the visual clues \& auditory direction and they went to the correct pathway. Universally, gamers' path was in the same trail. There were no distinct judgements and arguments on the clarification. When users found street sign, they heard an instruction to go direction as showed on the street sign, either took right or took left way. There is no difference clues between visually and auditory.

\section{Auditory Instruction without Sign System}

In this level, respondents asked to think their judgement with indirect visual aid. There was just auditory instruction as information for making decision. However, King (2009) states that there still has cross modal interaction since conflict information is occurred which provided by different senses, even though visual clue is disguised.

\section{a. Finding the Shelter Experiment}

The voice command was "Please find the shelter where the survivors could be there for having rest!". As showed in figure 6, we could estimate the location of shelter by guessing the form of shelter. There could be in the right hill or the left hill. I make aid for this discussion by placing red circle on the right hill, which is bunker ruins; and yellow circle for a cabana on the left hill. 


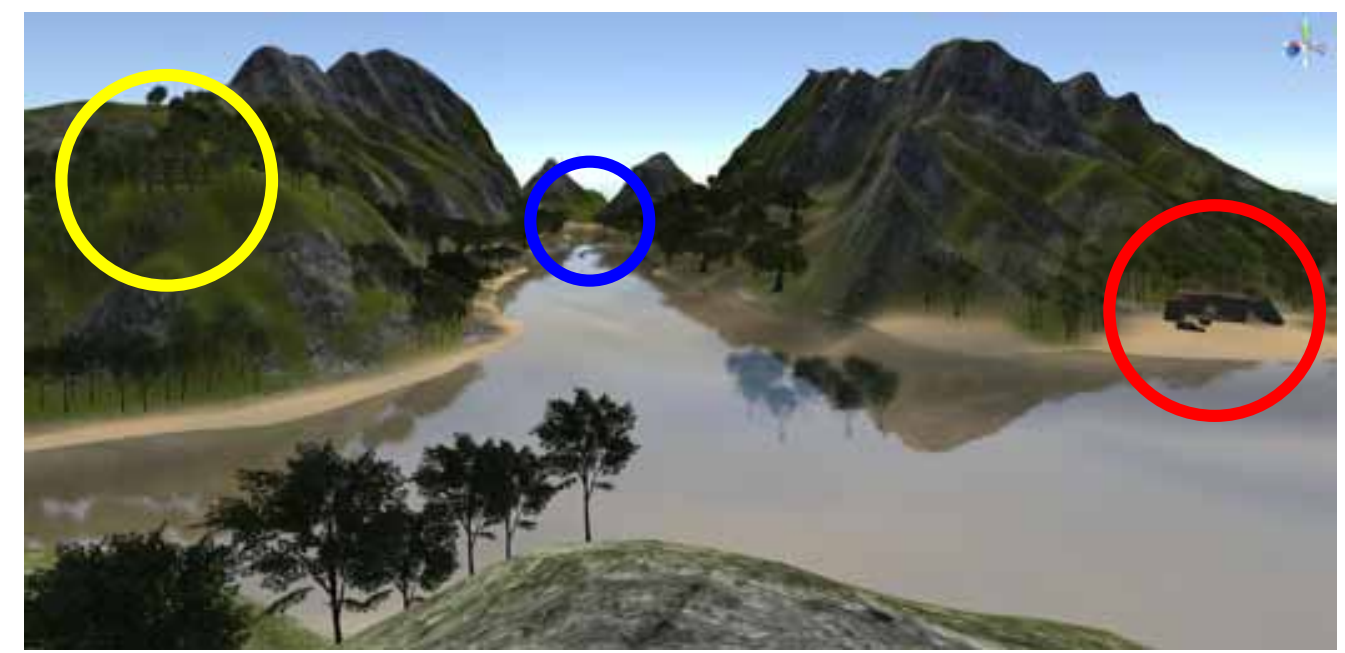

Figure 6. Finding The Survivors' Shelter

Based on the observation, 19 respondents went to the shelter where located on the left hill (yellow circle), 6 students chose the red circle shelter on the right hill, and interestingly, rest of 2 respondents went far away to the middle of valley (blue circle). The undirected two respondents did not give explanation on their decision.

\section{- The Cabana}

During interview for clarification, the 19 respondents said that ease to find the shelter due to form of the cabana on the left hill. Logically, the cabana was build as a shelter for mountain hikers \& villagers having rest. In addition, the respondents had information about the cabana and experienced use a cabana before. Visually, the cabana was located little bit difficult to see from distant position, especially, trees surrounding camouflaged it. However, the 19 respondents still recognised it as a cabana, which could be a shelter for the survivors.
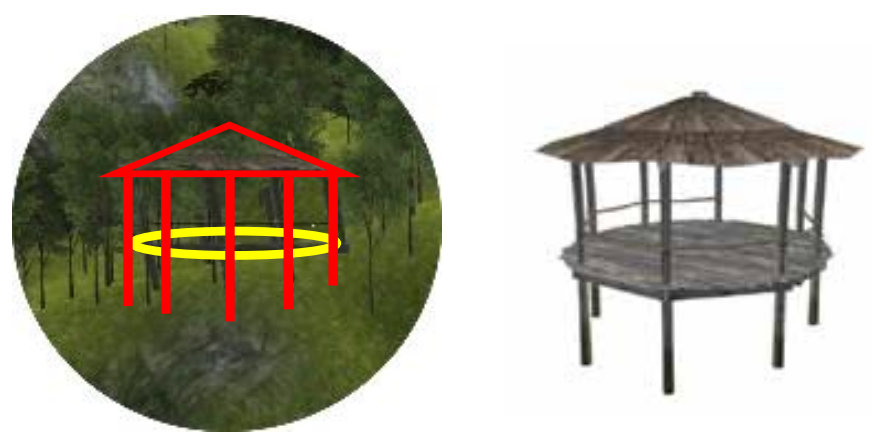

Figure 7. The Cabana

According to Solso (2003), eyes will attract to the objects due to mind perception. The mind's eye distorts an object influenced by the surrounding cues. The colour of environment enclose the object will aid eyes to recognise the name of the object. Furthermore, some researchers state that visual 
perception is caused by frequently seeing pattern and the edge of corners. As showed in figure 7, the left picture is the pattern of Cabana. This pattern helps respondents to recognise the cabana as a shelter in the game environment.

Captivatingly, the 19 students who chose the cabana in the game were explaining that the position of the cabana in left of the hill is also made easier and faster to find. I believe this visual perception is led by reading pattern that start from left hand side.

- The Bunker Ruins

The six respondents who chose the bunker ruins stated that the ruins could be a shelter for the survivors. At least, there is concrete as a cover from extreme weather. The reason is made sense, however, according to game scenario, there are some risks using the bunker ruins as a shelter. The survivors would unsafe due to sea tide (the bunker ruins is located in the seashore), the ruins have potentially collapsed, and wild animals.

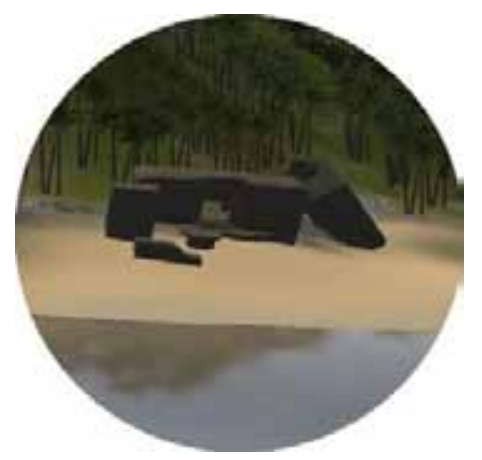

Figure 8. The Bunker Ruins

\section{b. Tracking the Path Experiment}

The game task in this position is tracking the potential lane of the lost people. There is no sign system that directs the players to both directions, as showed in figure 9. There are two hike trails, where both pointing to different peak of the hills. The auditory instruction gave command to the gamers for tracking the potential pathway of the survivors.

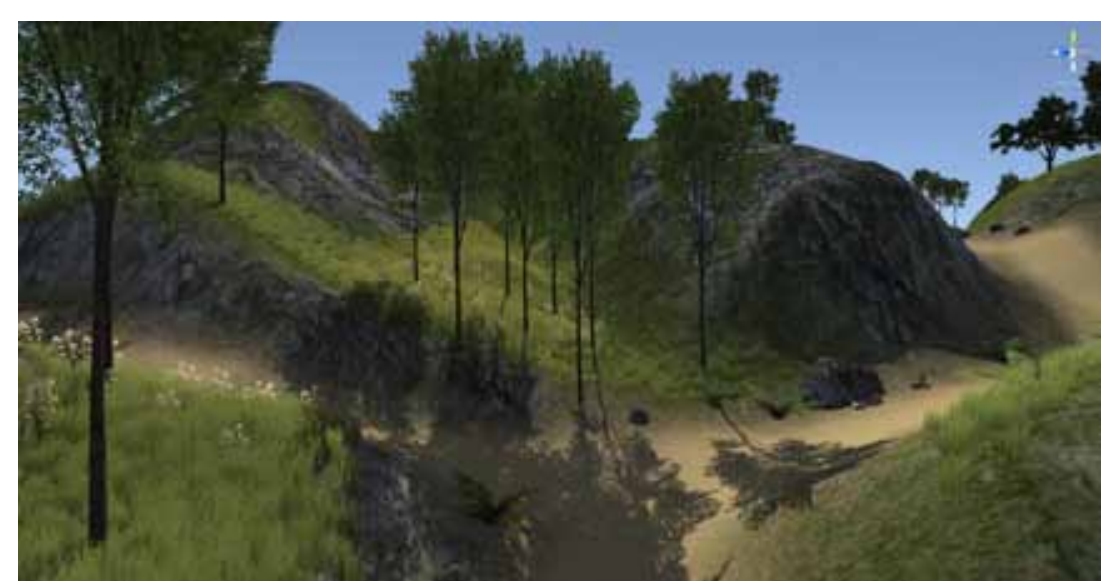

Figure 9. The Potentially Survivor's Path 
To sum up, the result of this section interview states that most of the respondents picked the right path and three students took the opposite pathway. The main reason that respondent decided to turn right, as potential pathway of the survivor, was finding garbage of food wraps and soft drink cans, looked at inset of figure 10. In SAR situation, that garbage could use as a marker and a possible indicator that the survivors just passed the track.

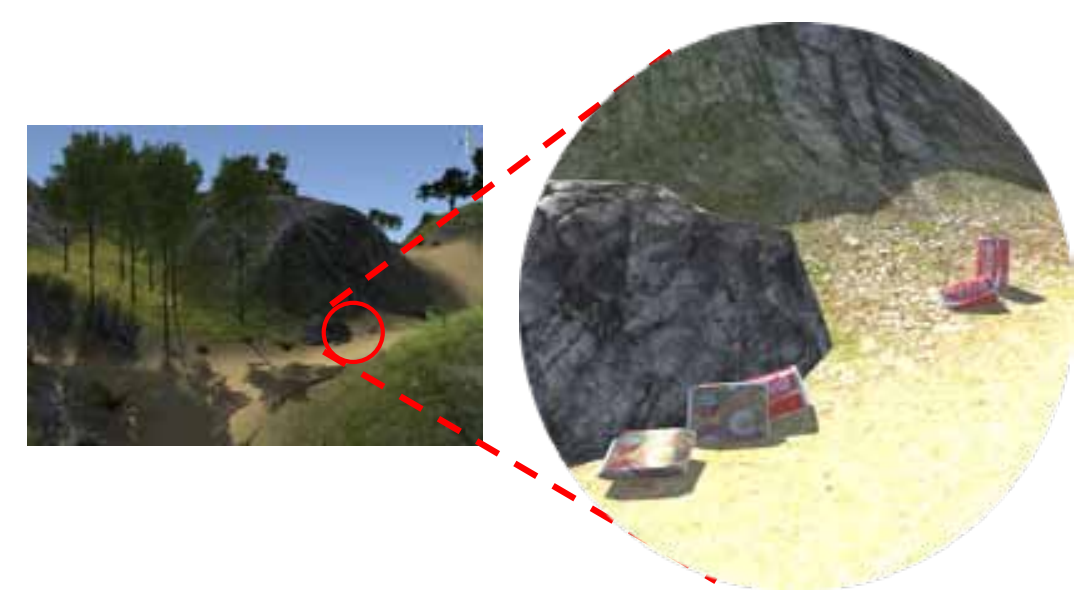

Figure 10. The Survivors' Marker

The rubbish of food wraps and cans is simple thing, however in the right place \& time, it leads great perception for human brain. Respectively, the visual perception guided someone for making decision. Minissale (2013) adding that human get visual perception in easy structure by identifying of such kind as line, colour, movement, luminance, and texture in the visual world. In my opinion, the respondents were making visual perception by differing the colour of the markers (food wraps \& cans), which they are red eye-catching, to the environment that dominate by natural colour (green \& brown). Furthermore, the visual sensation of presence is related to the fact that a perception of the object as a current one that we can cooperate with in our daily world (the perception of the surface) (Ferretti, 2017). As a result, the players can ease predict the potential survivors' track based on this visual perception.

\section{Paradoxical Clues}

The final level of experiment is applying the paradox of control on designing game. Essentially, the paradox of control is using cross modal of visual and auditory clues. The both of information are occurred simultaneously and contradictive each other. The challenges were separated in two levels, such as simple complexity and knotty complexity. The complexity were developed by multifaceted information that given to the respondents. Consequently, the players would assume multi interpretation on that information before making decision. 


\section{Simple Complexity}

The information on this situation used straightforward contradictive visual clues and auditory direction. For instance, visually directs to turn right and auditory asking to turn left. In the first experiment (figure 11), visually the respondents asked to turn left and simultaneously, the players heard auditory instruction "Please take the track by follow the bridge!", which was turning right.

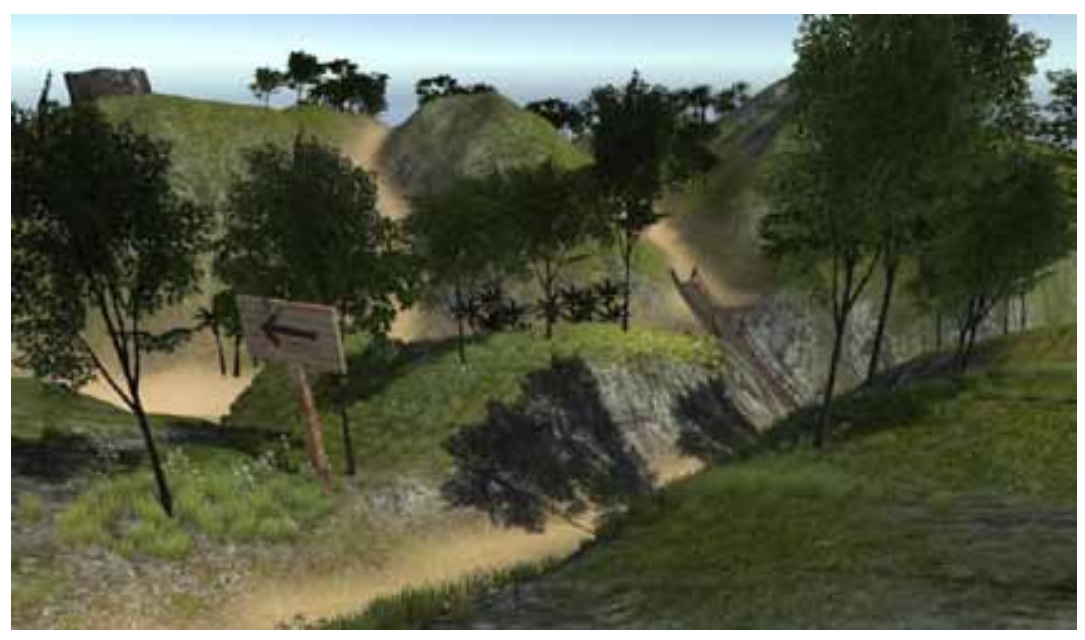

Figure 11. First Level of the Paradox of Control

I noted that the 23 respondents took to turn left by following street sign and the rest followed the auditory instruction. As showed in figure 11, there is no pathway if followed the sign system by turning left. Interestingly, the majority respondents still followed the sign system. Mostly the players stated that the street sign was more trusted differ to the easy pathway when followed the auditory direction. They thought that street sign was the proper way and would be the pathway for the survivor. This visual perception guided the respondents to take the imaginer confidence although it was not the correct one.

The result of this level observation is interesting. The respondents actually were gambling follow the signage. There was no track path and no destination information, however the players chose that way using their visual perception. The respondents defined that they focused on the SAR scenario and logic of survival by not going close to river if unnecessary, due to wild animal. Basically, when someone gets lost in the jungle or mountain, he/ she should hike to ridge, so it helps the lost person look the accessible pathway. On the other side, the gamers were making decision to turn left (following the sign system), it means they found the river. Actually, visual perception also gives unconsciously fast judgement before doing assessment, which is a negative condition that affects wrong decision. Minissale (2013) explains that the brain that associated with 
monitoring internal states and keeping long-term plan \& objective in mind also influences visual perception. In my opinion, sometime people does not consider with their short-term plan as a process of long-term achievement. Back to the result of observation, making decision by following the sign system is not long-term plan. It is just the way to achieve the long-term goal.

\section{b. Difficult Complexity}

In this paradoxical perception experiment, the complexities are multiple contradictive clues. The challenge consist visual clues, auditory instruction, environment clues/symbol, as showed in figure 12. The setting of this scenario is the players still seeking the survivors in the evening, close to the one of the summit with a cabana on it. Then the players heard auditory instruction, "Take another summit, probably you will find the survivors!". The result of observation, most of the respondents decided to take a cabana for camping, three students continued finding the survivors by turning to the right track, and the rest of two respondents followed the voice direction to 'jump-up' to other summit of the mountain.

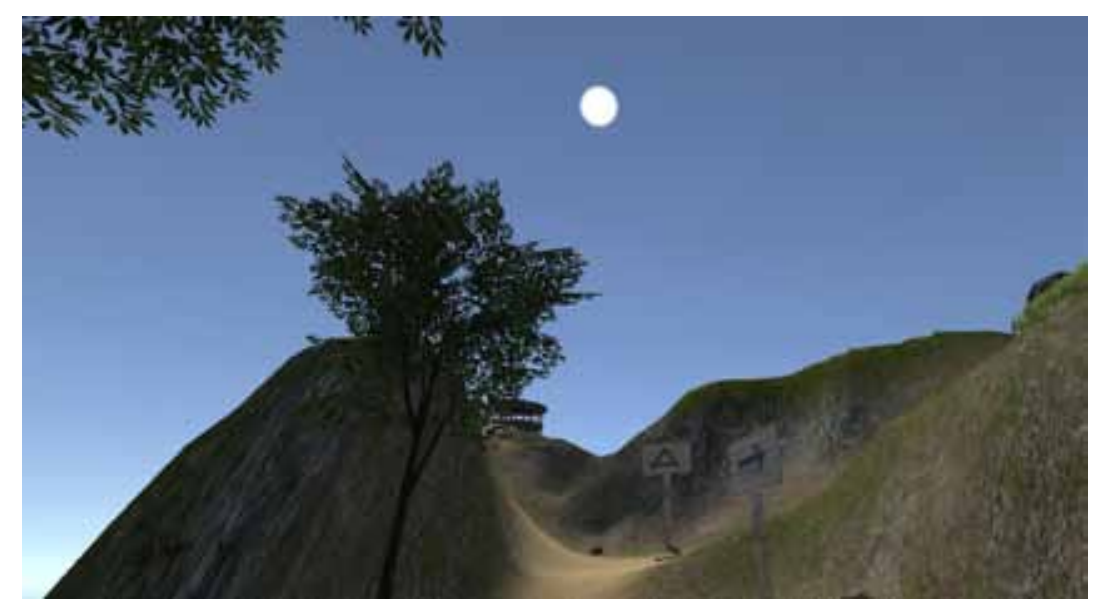

Figure 12. Complex Level of the Paradox of Control

I summarised the 22 players' statements who decided to camp on the cabana. Most of them have similar visual perception about the situation; first of all, there was an evening, difficult to find the survivors in the dark, even moonlight help illuminate the environment. Secondly, objects did not look bright, including the trail track, so they could not recognise the way properly. Thirdly, in the evening, eyes face hard to distinguish colour. As a result, the players could not recognise markers that left by the survivors. Lastly, naturally, the respondents assumed that working in the night were not effective. They had percept that the game system has artificial intelligence (AI) for limiting productivity of searching the survivors in the evening.

According to the players' arguments and perception, those are made sense. Let's we look at figure 12, there are some visual information that we could percept, such as: 
- A street sign to take right track

- A camping signage

- A cabana

- Moonlight

Reflection of moonlight from the sea behind the mountain

- Impression of slippery trail track

Those clues \& symbols could support the respondents' visual perception so their judgments are commonsense.

This paradoxical experiment states that visual clues give more perception compare to the auditory instruction. The voice information is happen once and unrepeatable, while the visual data is constant seen by the eyes. In addition, King (2009) explains this situation happen caused by the retinas send high-resolution and consistent information to the brain. It means the brain got prominent information for making-decision from its visual perception.

\section{CONCLUSION}

This study investigates paradoxical situation using cross modal visual and auditory clues. In general, the investigation found that a visual clue is more powerful for leading visual perception. Visually, the respondents followed street sign, street path, and game objects, such as building and others object/properties in the game world. Moreover, in case without visual clues, the respondents also followed the auditory command about which direction should be taken. The visual clues and auditory instructions were occurred randomly based on the path of the respondents' chosen. Interestingly, in circumstance of the paradox of control, most of the respondents decided to follow the visual clues, although it was not the right direction. The paradoxical cross modal using auditory instruction would not really affect the gamers' perception. Most of them are influenced by the visual clues for generating perception and making decision respectively. The logical terminology of visual perception in the gamers' head is greater than voice directions recognition. Finally, the game players' decisionmaking is predominantly triggered by visual perception. Recommendations from this study are; firstly, in designing game, visual aspect is more important. Secondly, the study needs to develop more detail, especially for going in depth investigation on the players' brain perception. Thirdly, conducting visual perception research using virtual reality technology.

\section{REFERENCES}

Bates, Bob. 2004. Game Design. Thomson Course Technology. $2^{\text {nd }}$ Edition

Csikszentmihalyi, Mihaly. 1990. Flow: The Psychology of Optimal Experience, New York: Harper \& Row Publishers, Inc.

Ferretti, Gabriele. 2017. Are Pictures Peculiar Objects of Perception?. Journal of the American Philosophical Association; Cambridge Vol. 3, Iss. 3 
Fullerton, Tracy. 2008. Game Design Workshop: A Playcentric Approach to Creating Innovative Games. Elsevier. $2^{\text {nd }}$ Edition

Gorini, A., Capideville, C.S., De Leo, G., Mantovani, F., \& Riva, G. 2011. The Role of Immersion and Narrative in Mediated Presence: The Virtual Hospital Experience. Cyberpsychology, Behavior and Social Network. Vol. 14, No. 3, 99-105.

King, Andrew J. 2009. Visual influences on auditory spatial learning. A Review, Philosophical Transactions of The Royal Society Biological Sciences

Meadows, M. S. 2003. Pause and Effect: The Art of Interactive Narrative. Pearson Education. San Francisco

Minissale, Gregory. 2013. The Psychology of Contemporary Art. Cambridge University Press

O'leary, Ann \& Rhodes, Gillian. 1984. Cross-Modal Effects On Visual and Auditory Object Perception. Perception \& Psychophysics. Volume 35, Issue 6, 565-569

Roettl, Johanna \& Terlutter, Ralf. 2018. The same video game in $2 D, 3 D$ or virtual reality - How does technology impact game evaluation and brand placements?. PLoS One. Vol. 13, Iss. 7. San Francisco

Solso, Robert L. 2003. The Psychology of Art and the Evolution of the Conscious Brain. MIT Press/Bradford Books Series

Tomaszewski, Zach. 2005. Foundations of Interactive Narrative. Retrieved from: http:// zach.tomaszewski.name/uh/ics699/intnarr.html

\section{GAME OBJECTS:}

UNITY3D. 2011. Island Demo Project. Downloaded from http://download.unity3d. com/gallery/demos/demos/IslandDemo.zip 